\title{
Proceeding
}

9th INSHS International Christmas Sport Scientific Conference, 4-6 December 2014. International Network of Sport and Health

Science. Szombathely, Hungary

\section{Situation awareness and complexity: the role of wearable technologies in sports science}

\author{
PIO ALFREDO DI TORE \\ Department of Human, Philosophical and Education Sciences (DISUFF), University of Salerno, Italy
}

\begin{abstract}
Di Tore, P.A. (2015). Situation awareness and complexity: the role of wearable technologies in sports science. J. Hum. Sport Exerc., 9(Proc1), pp.S500-S506. Situation Awareness is a key concept in activities in which cognitive and physical tasks are being performed in a complex system consisting of multiple humans and artifacts, under quickly changing conditions. The spread, in sports, of wearable technologies that can record and return in real time a wide variety of data related to the athlete and to the context provides a great opportunity to increase the level of Situation Awareness. Often, however, we are dealing with heterogeneous devices that work on very specific elements and, taken individually, are not sufficient to build an effective representation of the complexity of the phenomenon. The set of raw data in different formats and different levels of detail coming from the different wearable devices acquire real information value in the moment in which they are modeled according to semantic techniques. This paper proposes a framework that, due to semantic techniques, allows to transform a set of heterogeneous devices in a network of sensors that can guide decision making. Key words: SITUATION AWARENESS, DECISION MAKING, WEARABLE TECHNOLOGIES, SEMANTIC TECHNIQUES.
\end{abstract}

\footnotetext{
Corresponding author. University of Salermo, Via Casa Leone 7, Salerno, Italy

E-mail: alfredo.ditore@gmail.com

9th INSHS International Christmas Sport Scientific Conference, 4-6 December 2014. International Network of Sport and

Health Science. Szombathely, Hungary.

JOURNAL OF HUMAN SPORT \& EXERCISE ISSN 1988-5202

(c) Faculty of Education. University of Alicante

doi:10.14198/jhse.2015.10.Proc1.44
} 


\section{INTRODUCTION}

Situation Awareness is a key concept in activities in which cognitive and physical tasks are being performed in a complex system consisting of multiple humans and artefacts, under quickly changing conditions.

The concept of Situation Awareness was originally introduced by sports psychology of the 1970s, generally applied to team ball games. Theoretical work in sports psychology was focused on stimulus-response theory (Dickinson, 1976), perceptual cues (Abernethy \& Russell, 1984), and attentional style (Nideffer, 1976). In more recent times, this concept has been taken up and applied to a large area of scientific domains (Hone, Martin \& Ayres, 2006).

In sports science, the concept of Situation awareness was taken up again by Patrick, James, Ahmed, and Halliday, who, in a study about observational assessment of situation awareness, team differences and training implications, identified behavioural dimensions relevant to SA, subsumed under planning, problem solving, team coordination, attention, communication and knowledge (Patrick, James, Ahmed \& Halliday, 2006).

According to a widely accepted definition, Situation Awareness is "the perception of the elements in the environment within a volume of time and space, the comprehension of their meaning and the projection of their status in the near future" (Endsley, 1988). Endsley refers to a process divided into the three stages of perception, comprehension, and projection.

The perceptual level (1) concerns the collection of relevant environmental information, comprehension level (2) "encompasses how people combine, interpret, store, and retain information"; Comprehension level "includes more than perceiving or attending to information, but also the integration of multiple pieces of information and a determination or their relevance to the person's goals" (Endsley, 1988).

The last stage of the process, the projection level (3) instead involves "the ability to project from current events and dynamics to anticipate future events (and their implications)" and consequently "allows for timely decision making" (Endsley, 1988, p.100).

According to Orciuoli et al. "Situation Awareness represents a critical aspect for improving decision-making processes in several and heterogeneous domains like, for instance, Security (both cyber and physical), Emergency Management, Energy Savings, Logistics and so on. One of the most important steps in Situation Awareness is Situation Identification that is a challenging task" (Benincasa, D'Aniello, Gaeta, Loia \& Orciuoli, 2015).

\section{MATERIAL AND METHODS}

\section{Wearable Technologies and Sports Science}

The last decade has seen massive entrance of pervasive computing among sport-related technologies.

"Results over the last decade of research on applying ubiquitous computing technologies to enhance sports are encouraging. Researchers have learned a great deal about sensors and how to embed them in everyday objects. For example, accelerometers, gyroscopes, microphones, and cameras all lend themselves nicely to a range of sports applications. Computer vision algorithms are enabling researchers to 
analyze not only a single player's motions but also the patterns of a group of players simultaneously" (Rao, 2012).

The wearable technologies, in particular, are experiencing a rapid spread in performance analysis.

"Wearable sensors can be used to monitor the body's physiological response to exercise and also the kinematic aspects of performance. To monitor this in a natural way there is a need for integrated sensors that are comfortable, wearable and straightforward to use. Textile based sensors which are compatible with textile manufacturing processes are essential for such technology to become accessible" (Coyle, Morris, Lau, Diamond \& Moyna, 2009).

According to Helmer et al. "wearable devices extend the body in a real and virtual manner. The flow of information and stimuli from real - to - virtual, and virtual -to - real enable experiences to be shared across time and space. Wearable devices using textiles with embedded physiological sensors are used in various applications involving monitoring, control and learning". Helmer et al. discussed in particular the potential of interactive textiles to capture performance, accelerate learning, and connect the expertise of elite athletes and sports scientists with novices through the use of common virtual interactive models (Helmer et al., 2010).

An early literature review about Situation Awareness and wearable sensors is provided by Farringdon et al., who cited Picard and Healey for use of biometric sensors with wearable computers (Picard \& Healey, 1997) and Mann (Mann, 1996) for biometric monitoring for personal health in a wearable (Farringdon, Moore, Tilbury, Church \& Biemond, 1999).

As can be seen from the literature review, the topic is not new. As well, in two decades of practice, study and research, it is possible to say that, only a few years ago, wearable technologies in sports didn't have reached the transparent dimension desired by Norman in The Invisible Computer: "It should be quiet, invisible, unobtrusive. Yet it is all too visible, all too demanding. (Norman, 1999).

Early as 2005, Chi warned about the possible implications of using wearable sensors in sports.

"Adopting sensor technology in sports appears to operate on a similar set of evaluation factors as other areas of ubiquitous computing. Blindly developing sports technology without thinking how it affects players' behavior, judges' scoring choices, and spectator perceptions is a clear recipe for disaster" (Chi, 2005).

Nowadays, the rapid development of wearable technology and sensors allows to obtain an objective, accurate and non-invasive assessment of physical activity (Sgrò, Lo Bello \& Lipoma, 2009) and to collect data unobtrusively and without hindering movement or performance:

"Medicine and sports science require a close study of the functions of the body, whether by means of vital signs such as heartbeat and breathing, or by the movement and function of muscles and joints. Often they combine individual variables to determine further information that no one variable can provide. Such scrutiny of the body to determine its performance is often dependent on the environment in which the subject is being monitored. An athlete studied within laboratory conditions might perform quite differently from on the field" (Armstrong, 2007). 
In 2007, Armstrong wrote of the possible benefits of sensors to monitor a performance without changing the environmental conditions:

"The broad range of research that health and sports monitoring encompasses would benefit enormously from this ability to collect data unobtrusively and without hindering movement or performance. These data could relate information about the functioning of the body and the relative movement, in addition to any other performance-related data that might be desirable" (Armstrong, 2007).

The spread, in sports, of wearable technologies that can record and return in real time a wide variety of data related to the athlete and to the context provides a great opportunity to increase the level of Situation Awareness during competitions.

A conceptual framework

In the above presented Endsley model, perceiving context information means abstracting data coming from a set of sensors and sensor networks deployed in order to observe a specific environment (Benincasa et al., 2015).

Often, however, we are dealing with heterogeneous devices that work on very specific elements and, taken individually, are not sufficient to build an effective representation of the complexity of the phenomenon (Di Tore, D'Elia, Aiello, Carlomagno \& Sibilio, 2012; Carlomagno, Di Tore \& Sibilio, 2013; Di Tore, 2014).

The set of raw data in different formats and different levels of detail coming from the different wearable devices acquire real information value in the moment in which they are modeled according to semantic techniques.

In a work that has the stated aim of motivating "the usage of Linked Data and Situation Awareness techniques in order to support Seamless Learning scenarios", Orciuoli (Orciuoli, 2014) proposes a framework that although natively oriented learning, can also be extended to other fields of research.

In his work the author emphasizes how Situation Awareness and in particular Situation Recognition techniques can be studied and used to support the realization of different forms of ubiquitous access to information "using context-specific elements" (Orciuoli, 2014)

In the model proposed by Orciuoli (Fig. 1), the sensor networks are the infrastructure level that ensures the interaction between performer and environment and consist mainly of "sensors embedded in wearable devices" (Orciuoli, 2014). 


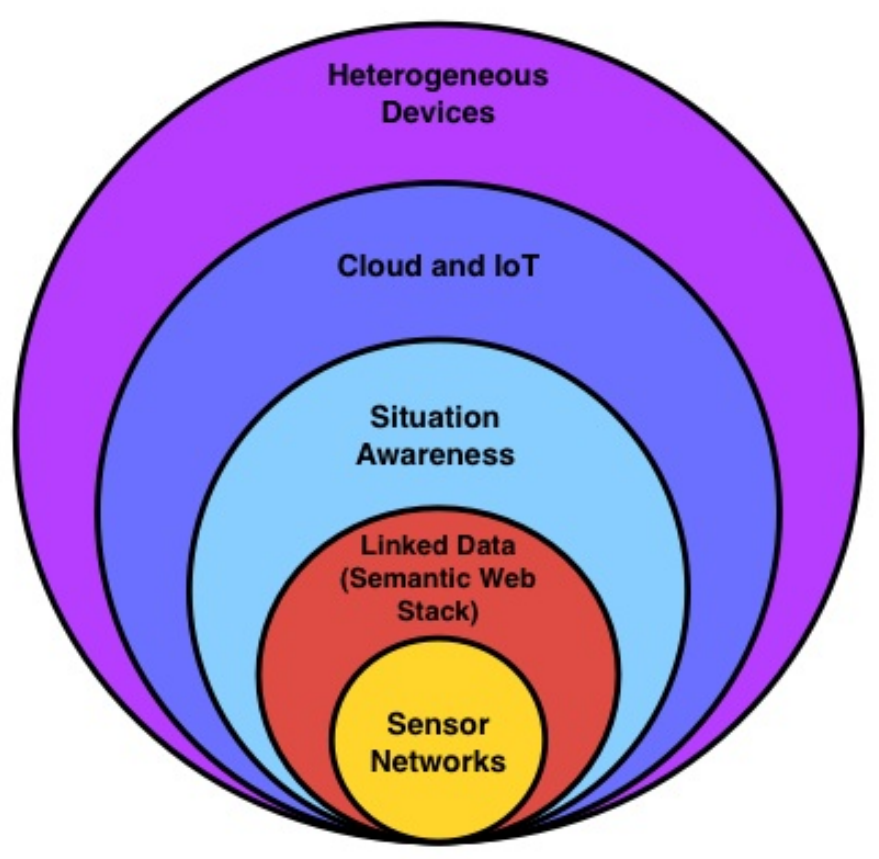

Figure 1. Semantic Technologies and Situation Awareness (Orciuoli, 2014)

Such sensor networks provide a rich variety of data on the environment and context, but they are obviously raw data in different formats and different levels of detail that acquire real informative value when they are modeled according to the techniques of the immediately above layer. In the proposed framework, in fact, Semantic Web allows to model and represent different types of information with respect to environment, domains, and activities (Orciuoli, 2014).

The layer in which the raw data collected by the sensor netwoks and modeled according to the methodologies and technologies acquire semantic meaning (are useful to guide the processes of decisionmaking) is precisely the Situation Awareness Layer.

In the proposed framework, Sensor Networks represent the infrastructure allowing to monitor the interaction with the environment, including sensors embedded in wearable devices.

Semantic Web Stack allows to model and represent different types of knowledge about environments. Moreover, the Linked Data approach is very useful to consider a bottom-up growth of semantic data.

Situation Awareness layer provides the facilities to interpret sensor (and other) data and automatically recognize the situation in which the performer is.

Cloud and loT (Internet of Things) Layer enable access to sensor networks and other deployed into the environment and to share and deliver resources and services across multiple and heterogeneous devices at anytime and anywhere (Orciuoli, 2014). 


\section{CONCLUSIONS}

The next-generation technologies provide a new way for collecting and processing of data related to athletes and to the context in which the athletes realize their performances. The use of the "perceptual" level of these technologies, combined with a framework able to make this data useful for the growth of Situation Awareness, seems to envisage a scenario able to actively support the Automatic Situation Recognition and consequently decision making.

Enactive Technologies (wearable technologies, body sensors, enactive interfaces) are well suited to a shift of paradigm centered on the concept of Situation Awareness (SA). The analysis of literature and of first experiences showed the need to define a framework able to return meaning to the ocean raw data potentially available in situation and use these data to adapt and improve performances.

\section{REFERENCES}

1. Abernethy, B., \& Russell, D. (1984). Advance cue utilization by skilled cricket batsmen. Australian Journal of Science and Medicine in sport, 16(2), pp.2-10.

2. Armstrong, S. (2007). Wireless connectivity for health and sports monitoring: a review. British journal of sports medicine, 41(5), pp.285-289.

3. Benincasa, G., D’Aniello, G., Gaeta, M., Loia, V., \& Orciuoli, F. (2015). Resilient Semantic Sensor Middleware. Intelligent Distributed Computing VIII, 571, pp.453-463.

4. Carlomagno, N., Di Tore, P.A., \& Sibilio, M. (2013). Motor activities teaching and complexity: a reversal of the classical description of the mechanisms of perception and action. Journal of eLearning and Knowledge Society, 9(3), pp.55-66.

5. Chi, E.H. (2005). Introducing wearable force sensors in martial arts. Pervasive Computing, IEEE, $4(3)$, pp.47-53.

6. Coyle, S., Morris, D., Lau, K.T., Diamond, D., \& Moyna, N. (2009). Textile-based wearable sensors for assisting sports performance. Wearable and Implantable Body Sensor Networks, 3-5 June. Berkeley: Congress Proceedings.

7. Di Tore, P.A. (2014). Perception of Space, Empathy and Cognitive Processes: Design Of A Video Game For The Measurement Of Perspective Taking Skills. International Journal of Emerging Technologies in Learning (iJET), 9(7), pp.23-29.

8. Di Tore, S., D'Elia, F., Aiello, P., Carlomagno, N., \& Sibilio, M. (2012). Didactics, movement and technology: new frontiers of the human-machine interaction. Journal of Human Sport and Exercise 7(1), pp.178-184.

9. Dickinson, J. (1976). A Behavioural Analysis of Sport. London, Lepus Books.

10. Endsley, M.R. (1988). Design and evaluation for situation awareness enhancement. Human Factors and Ergonomics Society Annual Meeting, 24-28 October. Anaheim: Congress Proceedings.

11. Farringdon, J., Moore, A.J., Tilbury, N., Church, J., \& Biemond, P.D. (1999). Wearable sensor badge and sensor jacket for context awareness. Wearable Computers, Digest of Papers. The Third International Symposium on, 18-19 October. San Francisco: Congress Proceedings.

12. Helmer, R., Mestrovic, M., Taylor, K., Philpot, B., Wilde, D., \& Farrow, D. (2010). Physiological tracking, wearable interactive systems and human performance. 20th Intl. Conf. on Artificial Reality and Telexistence, 1-3 December. Adelaide: Congress Proceedings. 
13. Hone, G., Martin, L., \& Ayres, R. (2006). Awareness-does the acronym "SA" still have any value. 11th International Command and Control Research and Technology Symposium, 26-28 September. Cambridge: Congress Proceedings.

14. Mann, S. (1996). Smart clothing: The shift to wearable computing. Communications of the ACM, 39(8), pp.23-24.

15. Nideffer, R.M. (1976). The inner athlete: Mind plus muscle for winning. New York: Crowell.

16. Norman, D.A. (1999). The invisible computer: why good products can fail, the personal computer is so complex, and information appliances are the solution. Cambridge: The MIT Press.

17. Orciuoli, F. (2014). Supporting Seamless Learning with Semantic Technologies and Situation Awareness. In X. F, B. L, P. F, K. M, \& L. V (Eds.), International Conference on Intelligent Networking and Collaborative Systems (INCOS). Los Alamitos, CA: IEEE Computer Society.

18. Patrick, J., James, N., Ahmed, A., \& Halliday, P. (2006). Observational assessment of situation awareness, team differences and training implications. Ergonomics, 49(4), pp.393-417.

19. Picard, R.W., \& Healey, J. (1997). Affective wearables. Personal Technologies, 1(4), pp.231-240.

20. Rao, V.K. (2012). Sports Education. New Delhi: APH Publishing Corporation.

21. Sgrò, F., Lo Bello, L., \& Lipoma, M. (2009). A networked embedded computing platform for physical activity assessment. $2^{\text {nd }}$ Conference on Human System Interactions, 21-23 May. Catania: Congress Proceedings. 